ISSN = 1980-993X - doi:10.4136/1980-993X
www.ambi-agua.net
E-mail: ambi-agua@agro.unitau.br
Tel.: (12) 3625-4212

\title{
Caracterização limnológica do reservatório hidrelétrico de Itumbiara, Goiás, Brasil
}

(http://dx.doi.org/10.4136/ambi-agua.191)

\author{
Renata Fernandes Figueira Nascimento ${ }^{1}$; Enner Alcântara ${ }^{1}$; Milton Kampel ${ }^{1}$; \\ José Luiz Stech ${ }^{1}$
}

\author{
${ }^{1}$ Instituto Nacional de Pesquisas Espaciais (INPE), Divisão de Sensoriamento Remoto \\ São José dos Campos - SP, Brasil \\ e-mail: re_ffnascimento@yahoo.com.br; \{enner, milton, stech\}@dsr.inpe.br
}

\section{RESUMO.}

O objetivo principal do presente trabalho é o de realizar a caracterização limnológica do reservatório de Itumbiara, GO, por meio de parâmetros limnológicos e radiométricos. Para tanto duas campanhas de campo foram realizadas, a primeira durante a estação chuvosa (maio) e a segunda durante a estação seca (setembro). Durante as campanhas de campo os seguintes parâmetros limnológicos foram medidos: clorofila-a, carbono orgânico dissolvido e inorgânico, material em suspensão total, temperatura da água, $\mathrm{pH}$ e turbidez. Os dados radiométricos foram coletados por meio de um espectrorradiômetro FieldSpec Hand Held. Além disso, foram medidos os coeficientes de absorção dos componentes opticamente ativos na água (COA) em laboratório. Os dados limnológicos foram interpolados utilizando-se o algoritmo de Krigeagem Ordinária e os dados radiométricos foram transformados em reflectância de sensoriamento remoto. Os coeficientes de absorção foram utilizados para construir um diagrama triangular com o objetivo de estudar a contribuição relativa de cada COA. Os resultados mostraram existir uma distinção espacial dos parâmetros limnológicos entre a região sob influência da barragem e a sob influência dos rios. Devido à baixa concentração de clorofila-a, a resposta espectral da água é fortemente afetada pela presença de partícula inorgânica em suspensão na água. O triângulo de contribuição relativa dos COA mostrou que a água no reservatório é dominada por matéria inorgânica particulada (entre 6580\%). Esses resultados permitem classificar a água do reservatório como sendo uma água do caso 2.

Palavras-chave: limnologia; bio-óptica; reflectância; águas do caso 2.

\section{Limnological characterization of the Itumbiara hydroelectric reservoir, Goiás, Brazil}

\section{ABSTRACT.}

The main objective of this work was to characterize the water properties of the Itumbaira, GO, hydroelectrically reservoir based on limnological and radiometric parameters. Two field campaigns were organized, the first during rainy (May) and the second in the wet season (September). In these field campaigns, the following limnological parameters were analyzed: chlorophyll-a, dissolved organic and inorganic carbon, total suspended matter, water temperature, $\mathrm{pH}$ and turbidity. The radiometric data were taken using a FieldSpec Hand Held portable spectroradiometer. Also the absorption coefficient of the optically active components (OAC) of the water were measured in laboratory. The limnological data was interpolated using Ordinary Kriging algorithm and the radiometric data were transformed in remote sensing reflectance. The absorption coefficient was used to build a triangular diagram 
NASCIMENTO, R. F. F.; ALCÂNTARA, E.; KAMPEL, M.; STECH, J. L. Caracterização limnológica do reservatório hidrelétrico de Itumbiara, Goiás, Brasil. Ambi-Agua, Taubaté, v. 6, n. 2, p. 143-156, 2011. (doi:10.4136/ambi-agua.191)

designed to verify the relative contribution of the OAC in water. The results show that there was a distinct spatial variation in the limnology of the area affected by the dam and the one under the river confluences. Due to the low chlorophyll-a concentration in water, the spectral response was strongly influenced by inorganic suspended particles. The triangulation of the absorption coefficient revealed that the water is dominated by the inorganic particulate matter (from 65 to 80\%). These results set the Itumbiara's water as case 2 water.

Keywords: limnology; bio-optics; reflectance; case 2 waters.

\section{INTRODUÇÃO}

Os reservatórios hidrelétricos são corpos d'água importantes para a produção de energia, atividades recreativas e esportivas, pesca comercial, controle de inundações e suprimento de água. A degradação desses sistemas aquáticos e da qualidade da água pode causar uma série de impactos ambientais. Devido ao uso e à ocupação do entorno, os reservatórios brasileiros têm apresentado alterações na qualidade de suas águas (Calijuri, 1999). A qualidade da água pode ser degradada pela presença de detritos, nutrientes, micro-organismos, pesticidas, metais pesados e sedimentos (Liu et al., 2003), causando com isso diversos problemas.

Esforços têm que ser empregados para evitar a degradação daqueles corpos que ainda estão em bom estado e para melhorar aqueles que já estão com problemas de degradação. Assim, pesquisas devem ser desenvolvidas para se entender os processos físicos, químicos e biológicos que atuam nesses ambientes e medidas mitigadoras devem ser sugeridas para conter o avanço da degradação. Diversos estudos têm sido realizados nesse sentido. Prado (2004) analisou espacial e temporalmente fatores relacionados ao uso e cobertura do solo no entorno, assim como parâmetros de qualidade da água do reservatório de Barra Bonita (SP). O estudo mostrou que, de 1990 a 2002, ocorreu um processo gradativo de expansão das fronteiras agrícolas e urbanas, comprometendo os remanescentes de vegetação natural e gerando uma carga maior de contaminantes que têm como destino os corpos d’água.

Muitas abordagens têm sido utilizadas para o estudo desses corpos d'água, tais como: uso de dados limnológicos coletados in situ, uso de dados radiométricos coletados próximos da superfície, sensoriamento remoto orbital, modelagem hidrodinâmica etc. O objetivo principal deste trabalho é utilizar dados de qualidade da água e radiométricos coletados in situ para uma melhor caracterização limnológica do reservatório de Itumbiara, GO.

Devido à grande importância desse reservatório, vários estudos relacionados à qualidade da água (Bazzoli et al., 1997; Hojo et al., 2004; Rosa, 2005; Mendonça, 2007; FURNAS, 2008; Vieira et al., 2009) e preservação ambiental (Oliveira, 2006; Lopes e Santos, 2002) foram realizados.

\section{MATERIAIS E MÉTODOS}

\section{1. Área de estudo}

O reservatório da Usina Hidrelétrica (UHE) de Itumbiara (18 $\left.{ }^{\circ} 25^{\prime} \mathrm{S}, 4^{\circ} 06^{\prime} \mathrm{W}\right)$ está localizado no bioma cerrado, na divisa dos estados de Minas Gerais, no Triângulo Mineiro, e Goiás. Foi formado pelo represamento do Rio Paranaíba, resultando na inundação de seus principais tributários, os Rios Corumbá e Araguari (Figura 1). Possui forma dendrítica, com $778 \mathrm{Km}^{2}$ de área inundada e um volume total de 17 bilhões $\mathrm{m}^{3}$ (Alcântara et al., 2010a). A profundidade média do reservatório, no período de cheia, é de aproximadamente $32 \mathrm{~m}$, durante a seca por volta de $22 \mathrm{~m}$ e a máxima pode chegar até $80 \mathrm{~m}$, as maiores profundidades se encontram próximas à barragem (Alcântara et al., 2010b). 
NASCIMENTO, R. F. F.; ALCÂNTARA, E.; KAMPEL, M.; STECH, J. L. Caracterização limnológica do reservatório hidrelétrico de Itumbiara, Goiás, Brasil. Ambi-Agua, Taubaté, v. 6, n. 2, p. 143-156, 2011. (doi:10.4136/ambi-agua.191)

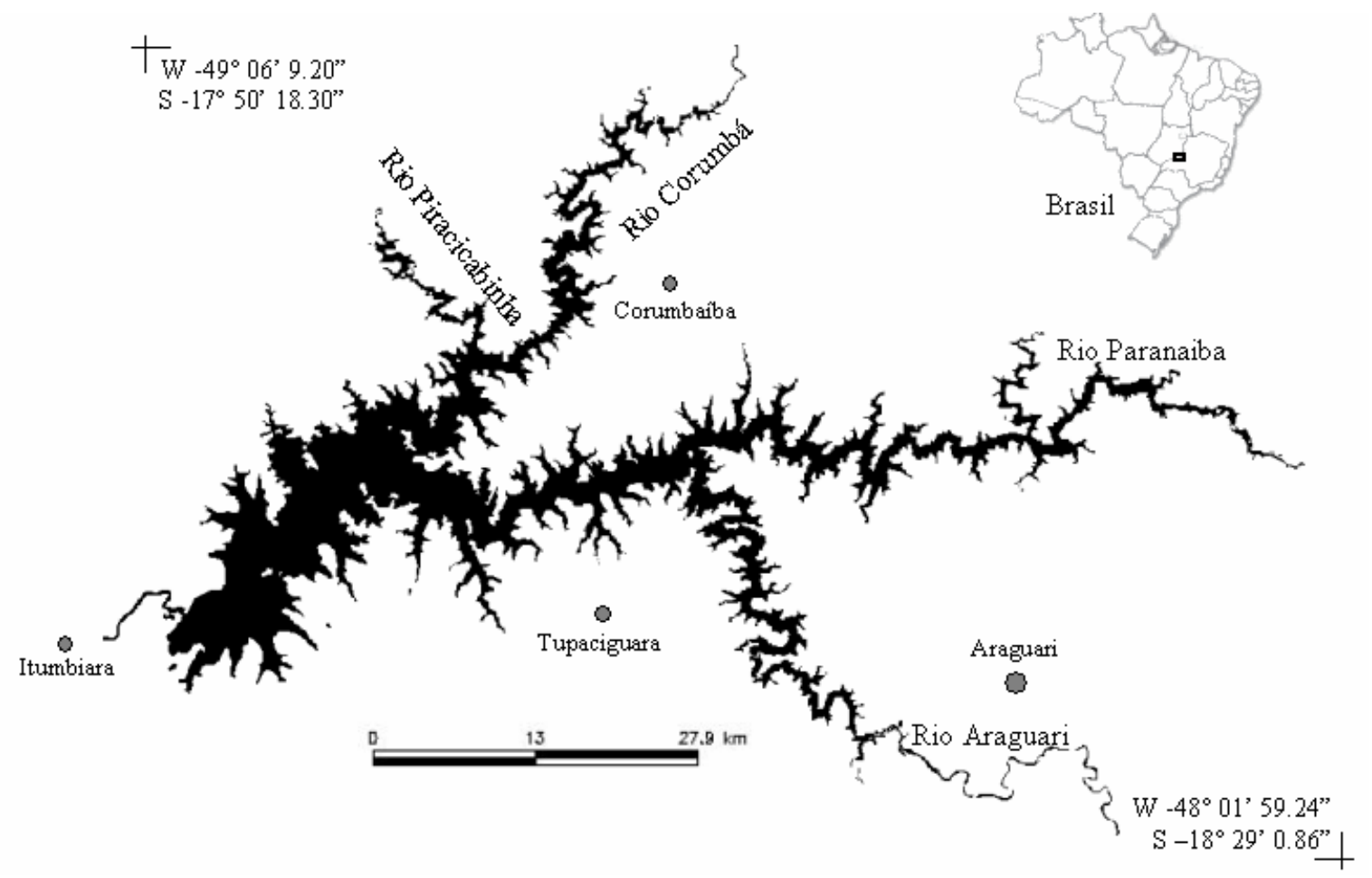

Figura 1. Localização do Reservatório de Itumbiara, os principais rios e as principais cidades.

O clima na região do reservatório é caracterizado por uma precipitação que varia de 2 mm durante a estação seca (maio - setembro) a 315 mm na estação chuvosa (outubro - abril). Durante a estação chuvosa, a intensidade dos ventos varia de 1,6 a 2,0 $\mathrm{ms}^{-1}$, podendo alcançar 3,0 ms-1 durante a estação seca (Figura 2-a). A temperatura do ar durante a estação chuvosa pode variar de 25 a $26,5^{\circ} \mathrm{C}$ e atingir o mínimo em junho $\left(21^{\circ} \mathrm{C}\right)$ na estação seca.
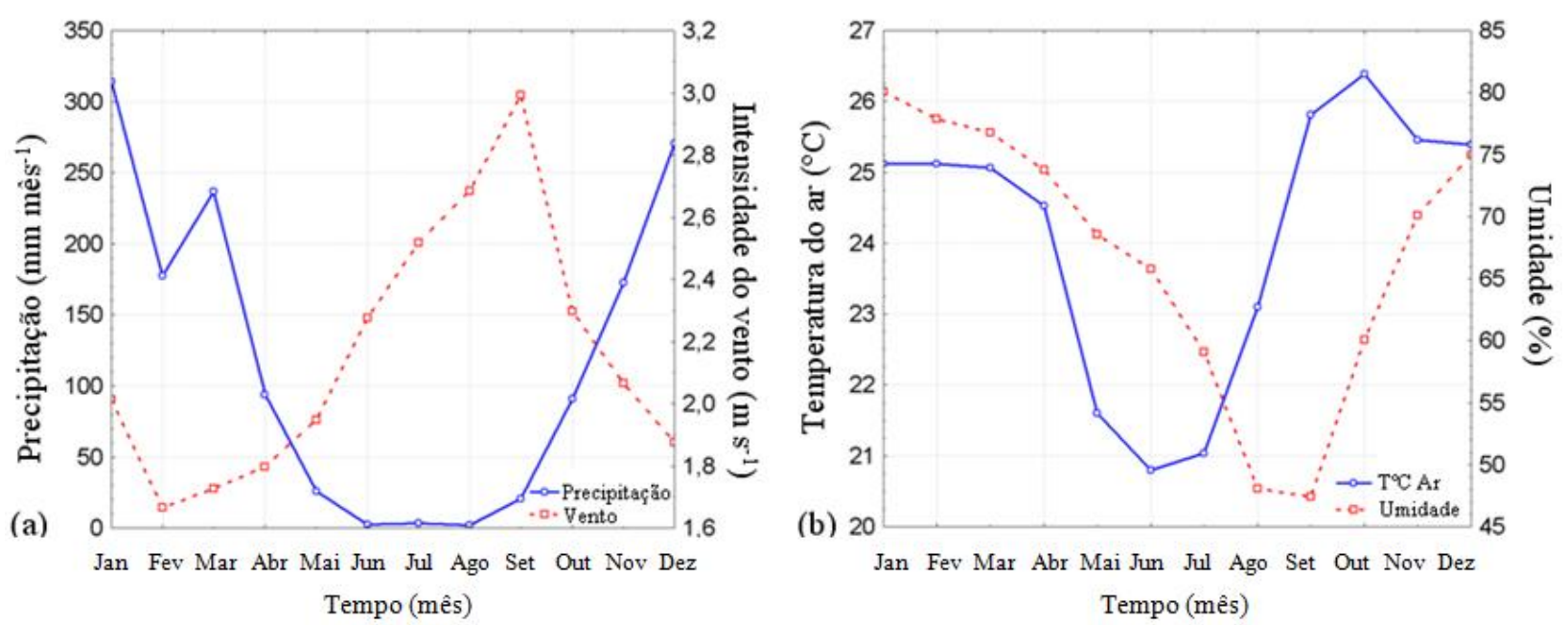

Figura 2. Caracterização climática da área do reservatório de Itumbiara por meio de uma média de 2003 a 2008.

Fonte: Alcântara et al. (2010b).

A umidade relativa do ar possui uma variação cujo padrão é simular à temperatura do ar, com uma pequena variação no valor mínimo em setembro (47\%); durante a estação chuvosa, a umidade pode atingir 75\% (Figura 2-b). O nível da água no reservatório pode ser observado na Figura 3. 
NASCIMENTO, R. F. F.; ALCÂNTARA, E.; KAMPEL, M.; STECH, J. L. Caracterização limnológica do reservatório hidrelétrico de Itumbiara, Goiás, Brasil. Ambi-Agua, Taubaté, v. 6, n. 2, p. 143-156, 2011. (doi:10.4136/ambi-agua.191)

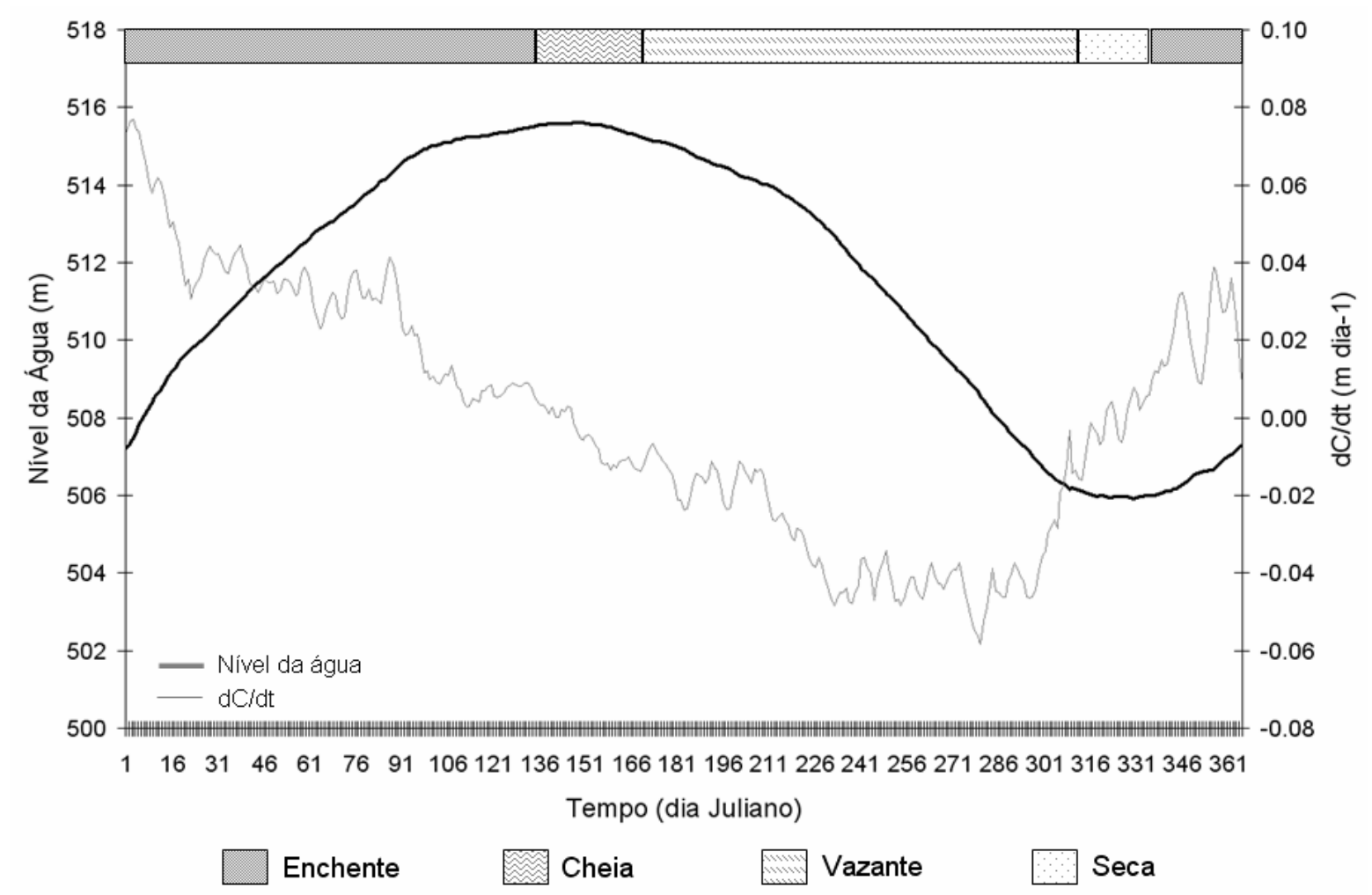

Figura 3. Variação média diária (2003-2008) do nível da água (C) no reservatório e sua variação no tempo $(t)$.

Fonte: Alcântara et al. (2010b).

Os dados de variação do nível da água foram utilizados como referência para o planejamento das campanhas de campo. Esse procedimento foi necessário para se garantir que as campanhas de campo fossem representativas de duas condições diferentes, ou seja, em um período seco e outro chuvoso.

\subsection{Campanhas de Campo}

Duas campanhas de campo foram realizadas na área de estudo, uma no período de cheia do reservatório (12 e 13 de maio de 2009) e outra no período de vazante (9, 10 e 11 de setembro de 2009).

\subsubsection{Planejamento amostral}

Para a determinação do local dos pontos amostrais, imagens do sensor MODIS adquiridas no site https://wist.echo.nasa.gov/api, do mês de maio de 2008, no mesmo mês da coleta de campo, porém do ano anterior, foram classificadas a fim de se obter uma verificação prévia dos tipos de água presentes no reservatório. Para essa classificação, foram analisadas tanto imagens da plataforma Aqua quanto Terra, de modo a contornar o problema de cobertura por nuvens na região do reservatório e obter imagens com melhor qualidade (sem ruídos). Inicialmente foram escolhidas imagens de 10/05 e 14/05/08 das duas plataformas.

A classificação foi realizada optando-se pela imagem do dia 10/05/2008 da plataforma Aqua. O produto escolhido foi o MYD09 referente à reflectância de superfície, sendo utilizadas as bandas $1(648 \mathrm{~nm}), 2(858 \mathrm{~nm}), 3(470 \mathrm{~nm}), 4(555 \mathrm{~nm}), 5(1240 \mathrm{~nm})$ e 7 (2130 $\mathrm{nm})$, excluindo-se a banda $6(1640 \mathrm{~nm})$ devido à presença de ruído. A imagem foi reamostrada de $500 \mathrm{~m}$ para $250 \mathrm{~m}$ no aplicativo MODIS Reprojection Tool (South Dakota School..., 2002), 
NASCIMENTO, R. F. F.; ALCÂNTARA, E.; KAMPEL, M.; STECH, J. L. Caracterização limnológica do reservatório hidrelétrico de Itumbiara, Goiás, Brasil. Ambi-Agua, Taubaté, v. 6, n. 2, p. 143-156, 2011. (doi:10.4136/ambi-agua.191)

Tendo em vista que o objetivo é identificar massas de água diferentes no reservatório, se fez necessário, criar uma máscara para separar água de terra firme. Isso teve por objetivo diminuir o tempo de processamento e evitar contaminação da terra durante a classificação. Essa máscara foi construída por meio da aplicação do algoritmo NDWI (índice de diferença normalizada da água) (Mcfeeters, 1996).

A classificação da superfície da água tem como princípio físico o comportamento espectral de uma determinada massa de água em que os componentes opticamente ativos (matéria inorgânica em suspensão, clorofila-a e matéria orgânica dissolvida) interagem com a radiação eletromagnética, e essa energia retorna ao sensor onde é registrada (Kirk, 1994).

O princípio desse tipo de classificação é que o classificador irá separar massas de água com composições diferentes, permitindo que os pontos amostrais sejam escolhidos de forma a melhor representar as características da água. A classificação das massas de água no reservatório foi realizada por meio do classificador não supervisionado K-médias (Bandyopadhyay e Maulik, 2002).

A distribuição dos pontos de coleta é mostrada na Figura 4, onde foram coletados dados limnológicos e radiométricos.

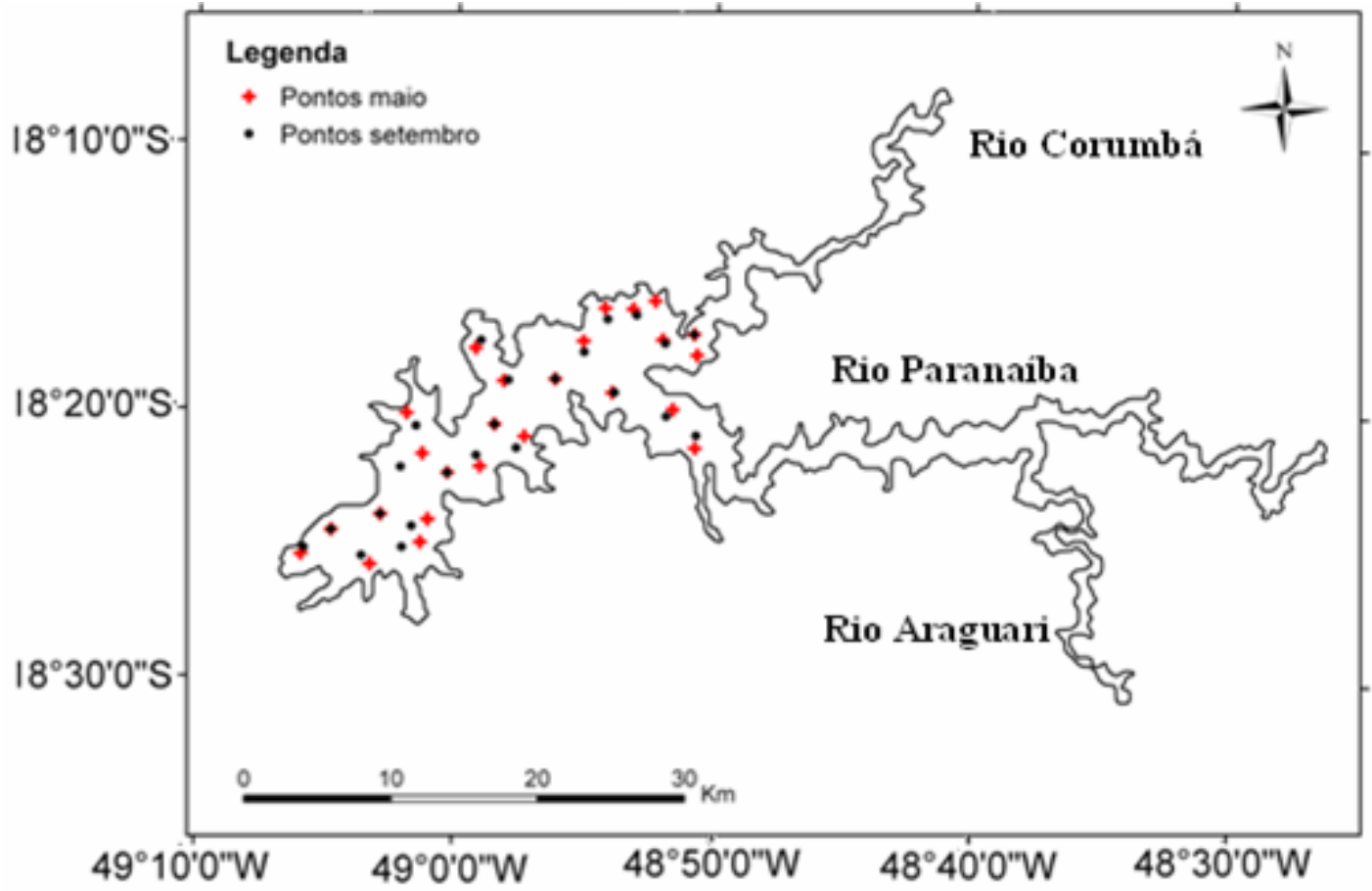

Figura 4. Localização dos pontos de amostragem durante os campos de maio e setembro de 2009.

\subsubsection{Dados limnológicos}

Amostras de água foram tomadas a uma profundidade de um metro, por meio de uma garrafa de Van Dorn. Essas amostras de água foram analisadas em laboratório com vistas a determinação dos seguintes parâmetros: concentração de clorofila- $a\left(\mu \mathrm{gL}^{-1}\right)$ de acordo com Nush (1980), material em suspensão orgânico e inorgânico $\left(\mathrm{mgL}^{-1}\right)$ de acordo com Wetzel e Likens (1991), e carbono orgânico e inorgânico dissolvido $\left(\mathrm{mgL}^{-1}\right)$ por meio do Analisador de Carbono Total SHIMADZU, modelo TOC-5000. Parâmetros como temperatura da água $\left({ }^{\circ} \mathrm{C}\right)$, pH e turbidez foram amostrados in situ por meio de uma sonda multiparâmetro YSI. 
NASCIMENTO, R. F. F.; ALCÂNTARA, E.; KAMPEL, M.; STECH, J. L. Caracterização limnológica do reservatório hidrelétrico de Itumbiara, Goiás, Brasil. Ambi-Agua, Taubaté, v. 6, n. 2, p. 143-156, 2011. (doi:10.4136/ambi-agua.191)

\subsubsection{Dados radiométricos}

Medidas radiométricas foram realizadas nos pontos amostrais em ambas coletas de campo, utilizando-se dois equipamentos. Para as medidas acima da superfície da água foi utilizado o radiômetro hiperespectral Fieldspec Hand Held, seguindo-se o protocolo de aquisição sugerido por Fougnie et al. (1999), sem polarizador.

Esse radiômetro possui campo de visada entre $5^{\circ}$ e $15^{\circ}$, resolução espectral de $3 \mathrm{~nm}$ e intervalo espectral de 350 a $1100 \mathrm{~nm}$. O cálculo da reflectância de sensoriamento remoto (Rrs) foi realizado de acordo com Mobley (1999). Detalhes dos procedimentos metodológicos podem ser acessados em Nascimento et al. (2009).

\subsubsection{Coeficiente de absorção dos componentes opticamente ativos}

Amostras de água também foram utilizadas para determinação dos coeficientes de absorção do material particulado (fitoplâncton e detritos), e da matéria orgânica dissolvida (CDOM), seguindo os protocolos de análise publicados pelo projeto SeaWIFS da NASA (National Aeronautics and Space Administration) (Mueller et al., 2002).

A partir dos valores dos coeficientes de absorção específicos, dos componentes opticamente ativos (COAs), estabelecidos por filtração e leitura de amostras coletadas em campo, foi construído um diagrama triangular indicando a contribuição relativa de cada componente na água do reservatório. Essa classificação é baseada nas contribuições relativas dos três tipos de substâncias e não depende da magnitude das contribuições individuais. A contribuição da água pura não entra na classificação, já que seu coeficiente de absorção é uma propriedade óptica constante. Assim, as amostras foram classificadas com base nas contribuições relativas dos três componentes opticamente ativos, no comprimento de onda de $440 \mathrm{~nm}$ (comprimento de onda no qual todos os componentes são opticamente importantes) (Prieur e Sathyendranath, 1981), e os resultados foram plotados em um diagrama triangular. Esse procedimento foi realizado para 20 pontos amostrais em maio e 23 pontos em setembro.

\subsection{Estrutura espacial dos dados}

Os dados limnológicos foram interpolados por meio do algoritmo de Krigeagem Ordinária com modelo de variograma linear, com o objetivo de analisar sua estrutura espacial (Journel, 1988). A krigeagem compreende um conjunto de técnicas de estimação e predição de superfícies baseada na modelagem da estrutura de correlação espacial. O que diferencia a krigeagem de outros métodos de interpolação é a estimação de uma matriz de covariância espacial que determina os pesos atribuídos às diferentes amostras, o tratamento de redundância dos dados, a vizinhança a ser considerada no processo inferencial e o erro associado ao valor estimado (Camargo et al., 2004). inferencial e o erro associado ao valor estimado (Camargo et al., 2004). Portanto, a grande diferença é a maneira como os pesos são atribuídos às diferentes amostras. No caso da interpolação por média simples, por exemplo, os pesos são todos iguais a 1/N ( $\mathrm{N}$ = número de amostras); na interpolação baseada no inverso do quadrado das distâncias, os pesos são definidos como o inverso do quadrado da distância que separa o valor interpolado dos valores observados. Na krigeagem, o procedimento é semelhante ao de interpolação por média móvel ponderada, exceto que aqui os pesos são determinados a partir de uma análise espacial, baseada no semivariograma experimental. A krigeagem possibilita inferência de valores a partir de amostras pontuais de um atributo espacial. Essas inferências são usadas, geralmente, para finalidades de mapeamento digital de atributos espaciais (Journel, 1988; Felgueiras, 1999). 
NASCIMENTO, R. F. F.; ALCÂNTARA, E.; KAMPEL, M.; STECH, J. L. Caracterização limnológica do reservatório hidrelétrico de Itumbiara, Goiás, Brasil. Ambi-Agua, Taubaté, v. 6, n. 2, p. 143-156, 2011. (doi:10.4136/ambi-agua.191)

\section{RESULTADOS E DISCUSSÃO}

Os resultados serão apresentados em três seções, obedecendo à seguinte ordem: (a) análise dos dados limnológicos obtidos in situ e analisados em laboratório, (b) dados limnológicos obtidos in situ por meio de uma sonda YSI, (c) dados de radiometria da água e (d) a contribuição relativa dos componentes opticamente ativos na água do reservatório.

\subsection{Dados de laboratório}

Concentração de clorofila-a: a maior concentração de clorofila-a no reservatório foi observada durante o mês de setembro $\left(10,02 \mu \mathrm{gL}^{-1}\right)$ e a menor, no mês de maio $\left(2,70 \mu \mathrm{gL}^{-1}\right)$. No mês de maio, a região sob transição do rio Araguari com o reservatório foi onde ocorreram as maiores concentrações e os menores na porção norte (Figura 5-a). No mês de setembro, as maiores concentrações também foram encontradas na transição do rio Araguari, assim como em toda a porção sul do reservatório. As menores concentrações se concentraram na entrada do rio Paranaíba e próximo à barragem.

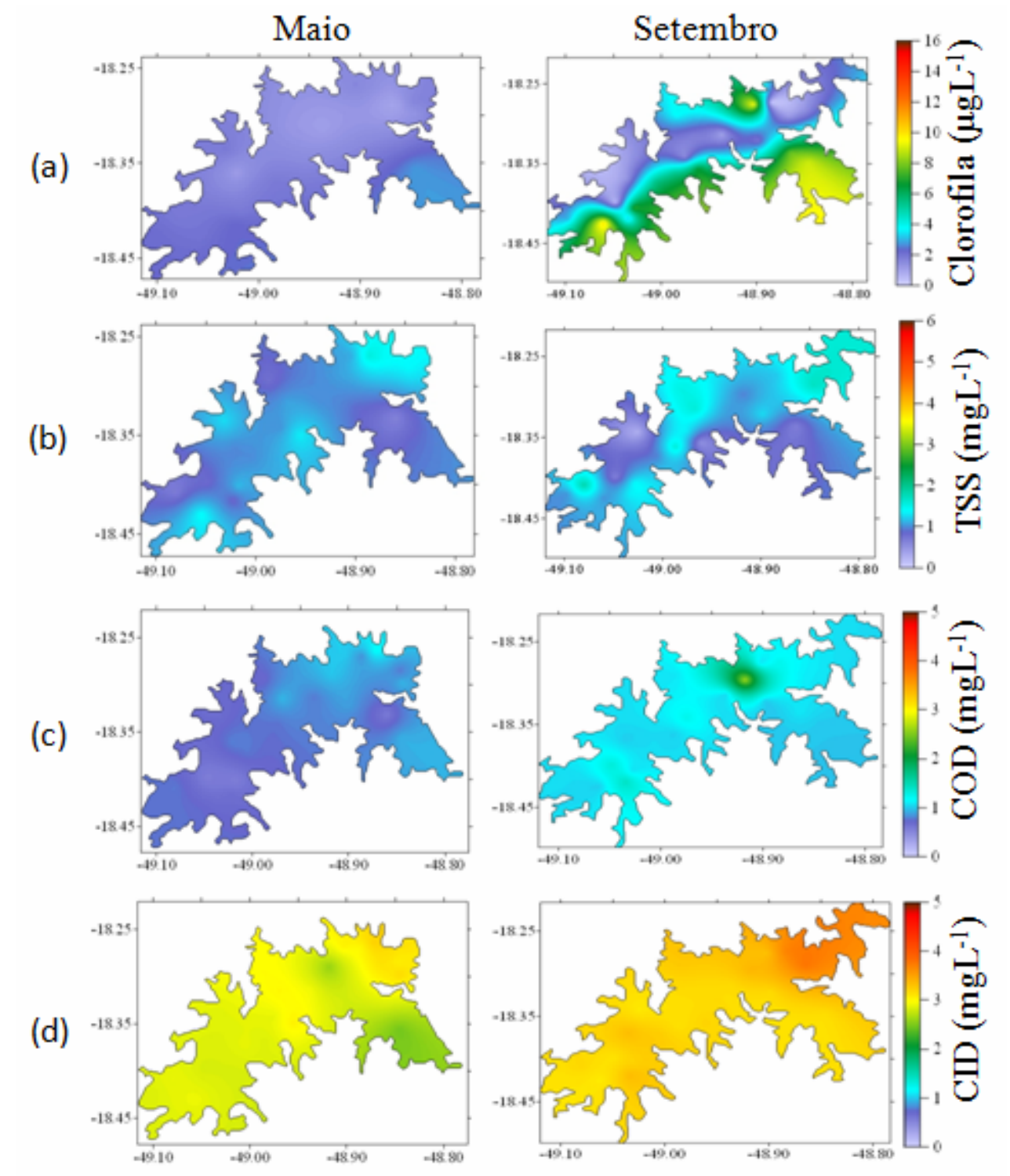

Figura 5. Distribuição espacial dos parâmetros obtidos em laboratório nos meses de maio e setembro: (a) clorofila-a, (b) total de sólidos em suspensão (TSS), (c) carbono orgânico dissolvido (COD) e (d) carbono inorgânico dissolvido (CID). 
NASCIMENTO, R. F. F.; ALCÂNTARA, E.; KAMPEL, M.; STECH, J. L. Caracterização limnológica do reservatório hidrelétrico de Itumbiara, Goiás, Brasil. Ambi-Agua, Taubaté, v. 6, n. 2, p. 143-156, 2011. (doi:10.4136/ambi-agua.191)

Total de sólidos em suspensão (TSS): o TSS no reservatório não se alterou de maio a setembro, mostrando que os valores máximos são muito próximos, $1,54 \mathrm{mgL}^{-1}$ e $1,81 \mathrm{mgL}^{-1}$, respectivamente (Figura 5-b). Os dados interpolados mostram que parece ocorrer um padrão de distribuição do TSS no reservatório, provavelmente devido ao padrão de vento na região. Ou seja, a figura mostra que o TSS parece ter um 'caminho' que se estende do Rio Paranaíba até a barragem.

Carbono orgânico dissolvido (COD): o COD tem maior concentração no mês de setembro (máximo de 2,59 $\mathrm{mgL}^{-1}$ ) e menor em maio (máximo de 1,17 $\mathrm{mgL}^{-1}$ ). Em maio, é possível observar que a concentração de COD aumenta de leste para oeste, ou seja, dos rios para o centro do reservatório. Isso mostra que devido às chuvas e à ação do vento, a maior fonte de COD no reservatório vem da bacia de drenagem (Figura 5-c).

Carbono inorgânico dissolvido (CID): assim como o COD, o CID também apresenta maiores concentrações em setembro (máximo de 3,76 $\mathrm{mgL}^{-1}$ ) em relação a maio (máximo de $3,22 \mathrm{mgL}^{-1}$ ). No caso de setembro essas altas concentrações estão concentradas na transição do rio Paranaíba com o reservatório (Figura 5-d). Já no caso maio se verifica que a transição rio Araguari com o reservatório é o que apresenta menor concentração.

\subsection{Dados da sonda}

Turbidez: apresenta maior turbidez durante o mês de maio, com valor máximo de 6,30 NTU; em setembro, a turbidez é quase 5 vezes menor (Figura 6-a). Em maio, a turbidez é maior na confluência do rio Paranaíba e menor próximo à barragem. Em setembro, é maior nos rios Paranaíba e Araguari e menor no corpo principal do reservatório. Esse comportamento é devido a maio ser um período chuvoso o que traz por meio de escoamento superficial material de origem terrestre para dentro do reservatório.

$p H$ : em média o $\mathrm{pH}$ de ambos os meses em análise apresentam valores muito próximos (maio $=7,63$ e setembro $=6,99$ ). No entanto, o pH no mês de maio é mais homogêneo com pouco gradiente horizontal; ao passo que no mês de setembro o $\mathrm{pH}$ se apresenta compartimentalizado (Figura 6-b). A grande diferença entre maio e setembro são os locais onde os maiores valores de $\mathrm{pH}$ ocorrem. Em maio, esses valores estão mais concentrados nos rios e, em setembro, na região próxima à barragem.

Temperatura da água: a temperatura da água é maior durante o período chuvoso (maio) e menor durante o período de estiagem (setembro). Essa diferença de temperatura se deve, principalmente, à maior radiação de onda curta e temperatura do ar durante o período chuvoso (Alcântara et al., 2010a). Durante o período de estiagem, a temperatura da água é menor devido à menor radiação de onda curta. Além disso, durante o período de estiagem, o reservatório pode sofrer influência de frentes frias (Alcântara et al., 2010c). Em setembro, pouco gradiente horizontal existe (Figura 6-c). Em maio, existe uma diferença de temperatura entre a região próxima da barragem e as outras regiões do reservatório que chega a aproximadamente $4^{\circ} \mathrm{C}$.

\subsection{Dados de radiometria da água}

As curvas de Reflectância de Sensoriamento Remoto (Rrs) coletadas em maio e setembro podem ser observadas na Figura 7. Para os dois períodos de coleta, as curvas apresentaram um pico entre 500 e $600 \mathrm{~nm}$, mostrando uma provável influência por sedimentos inorgânicos em suspensão, pois o espectro de águas dominadas por esse componente apresenta um aumento na reflectância, principalmente, na região entre 580 e 680 nm (Novo et al., 1991).

A resposta espectral do sedimento em suspensão também varia de acordo com sua granulometria (Cabral et al., 1990) e a origem e cor do sedimento, entretanto no intervalo de 550 a $570 \mathrm{~nm}$ é observado um espalhamento maior (Choubey e Subramanian, 1991; Gitelson e Keydan, 1990). 
NASCIMENTO, R. F. F.; ALCÂNTARA, E.; KAMPEL, M.; STECH, J. L. Caracterização limnológica do reservatório hidrelétrico de Itumbiara, Goiás, Brasil. Ambi-Agua, Taubaté, v. 6, n. 2, p. 143-156, 2011. (doi:10.4136/ambi-agua.191)

As curvas espectrais encontradas se assemelham as curvas encontradas por Liew et al. (1999), com baixas concentrações de clorofila e de sedimentos em suspensão. No mês de setembro, observa-se um achatamento do pico. Goodin et al. (1993) demonstraram, ao estudar a resposta fitoplanctônica, que as curvas de reflectância sofrem um deslocamento de um pico bem definido em $550 \mathrm{~nm}$, quando a água está pouco túrbida, para um pico mais extenso e achatado que vai de $550 \mathrm{~nm}$ a $650 \mathrm{~nm}$ em águas com níveis mais altos de turbidez. Esse resultado mostra o mascaramento do pico na faixa do verde devido aos sedimentos em suspensão.

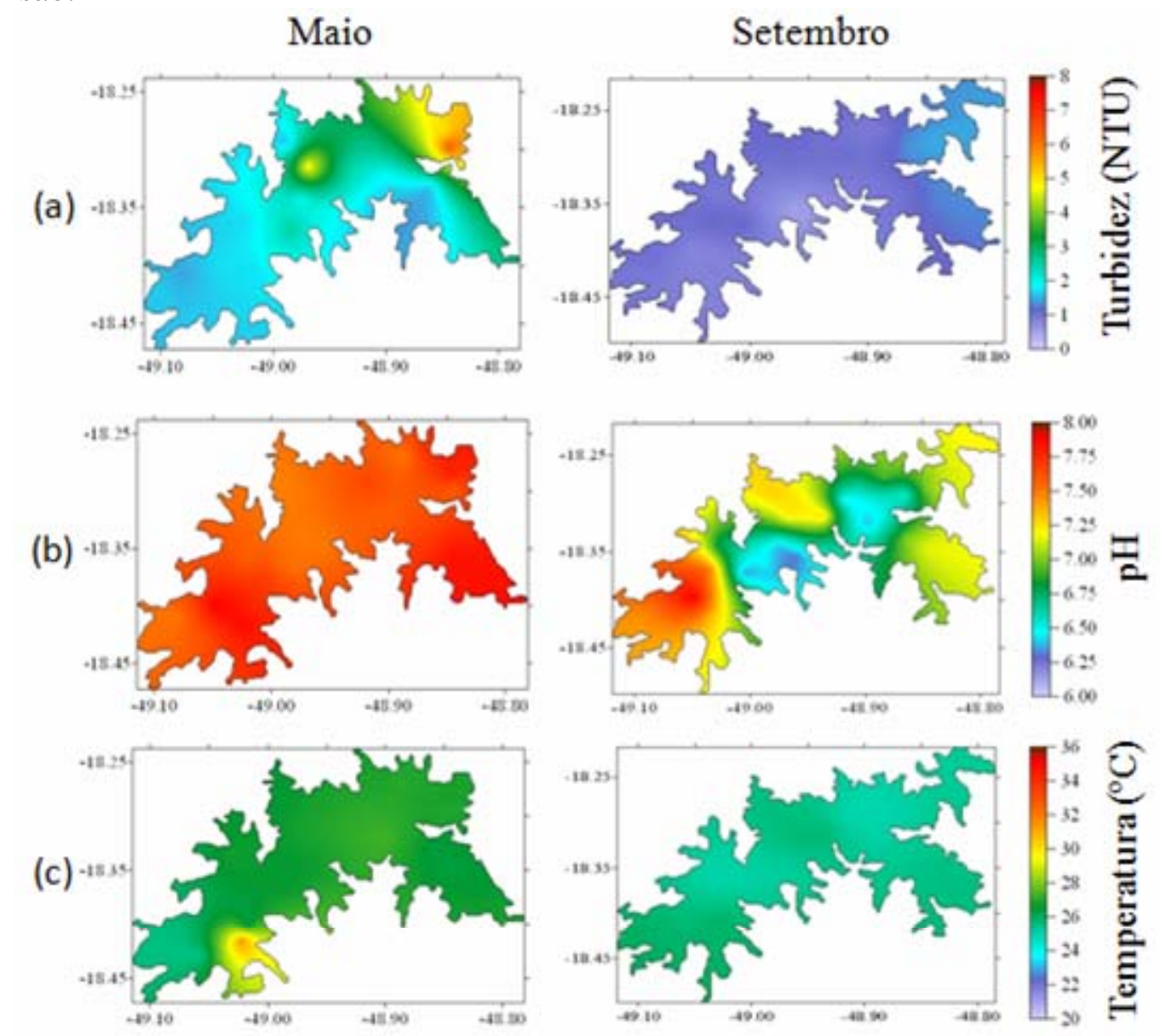

Figura 6. Distribuição espacial dos parâmetros obtidos por meio de uma sonda YSI nos meses de maio e setembro: (a) turbidez, (b) pH e (c) temperatura da água.
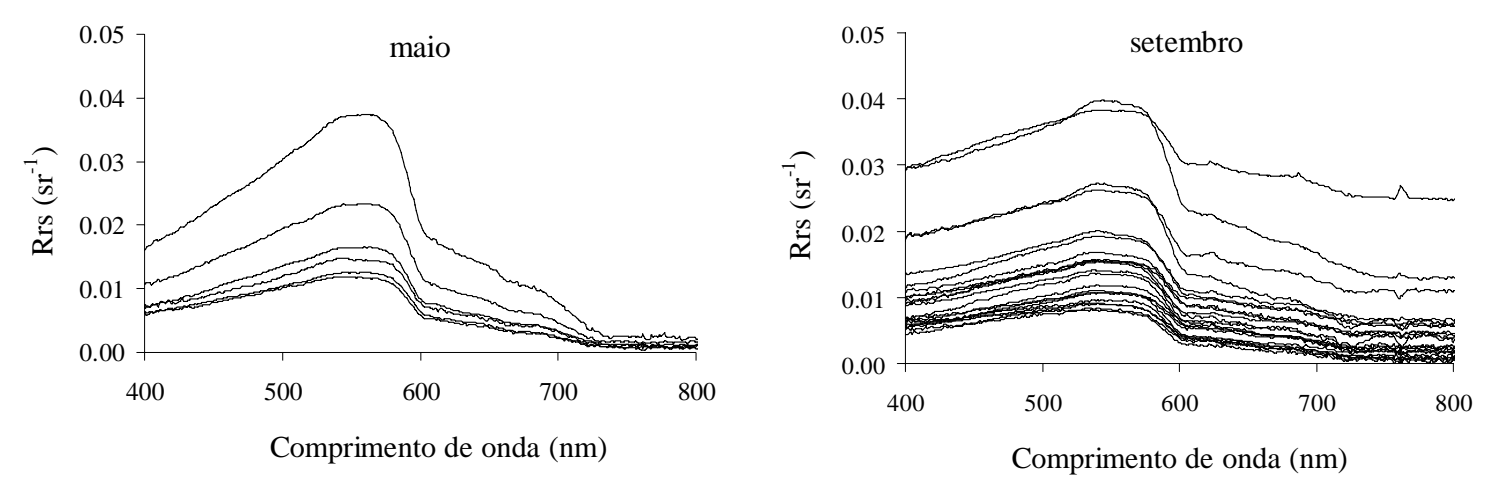

Figura 7. Espectros de Rrs obtidas em campo nos meses de maio e setembro de 2009. 
NASCIMENTO, R. F. F.; ALCÂNTARA, E.; KAMPEL, M.; STECH, J. L. Caracterização limnológica do reservatório hidrelétrico de Itumbiara, Goiás, Brasil. Ambi-Agua, Taubaté, v. 6, n. 2, p. 143-156, 2011. (doi:10.4136/ambi-agua.191)

\subsection{Contribuição relativa dos componentes opticamente ativos}

A partir dos coeficientes de absorção dos componentes opticamente ativos da água, foi construído um diagrama triangular, indicando as importâncias relativas de cada componente, para as duas saídas de campo. A Figura 8 mostra qual o componente dominante nos dois períodos de coleta.

Nos dois períodos de coleta, fica evidente a dominância por detritos, ou seja, a parte inorgânica do material particulado. No mês de maio, algumas amostras indicam uma maior contribuição de matéria orgânica dissolvida. Esse resultado corrobora os dados de $R r s$ medidos em campo, demonstrados na Figura 7. Em quase todas as amostras analisadas, em maio e setembro, os detritos contribuíram com mais de $50 \%$ para a absorção total (descontando-se àquela pela água pura). O fitoplâncton contribui, em média, com um pouco mais de $20 \%$ de todas as coletas. O CDOM apresentou a menor contribuição relativa, ficando abaixo dos $40 \%$ em maio, e dos $25 \%$ em setembro. Essa aparente maior contribuição do CDOM em maio se deve ao fato de duas amostras apresentarem valores altos de contribuição relativa, cujos pontos amostrais se localizam próximos ao rio Corumbá. De acordo com a metodologia proposta por Prieur e Sathyendranath (1981), a água do reservatório de Itumbiara pode ser classificada como do Caso 2, dominada por detritos.

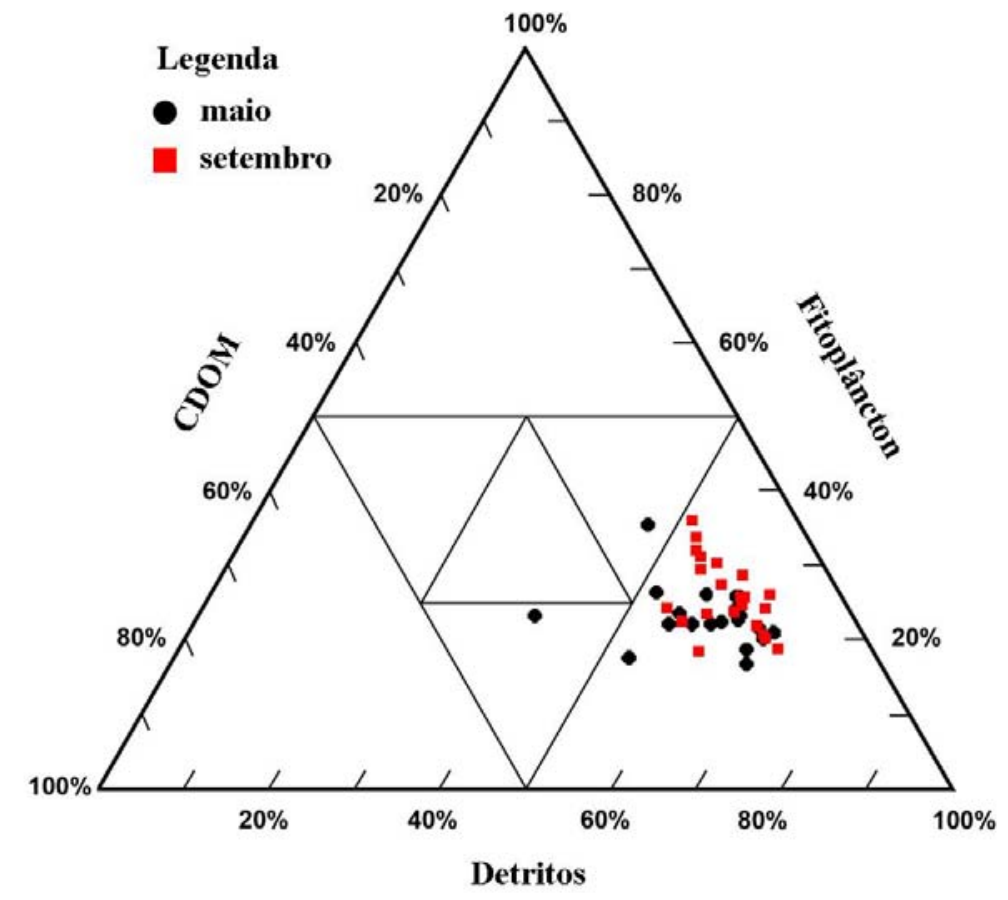

Figura 8. Diagrama ternário indicando a importância relativa de cada componente opticamente ativo. Círculos pretos indicam dados do mês de maio, e quadrados vermelhos indicam dados do mês de setembro.

\section{CONCLUSÃO}

De acordo com os resultados encontrados da análise de dados in situ, conclui-se que o componente opticamente ativo dominante no reservatório de Itumbiara é o material particulado inorgânico, nos dois períodos de coleta, cheia e vazante. Caracterizando a água do reservatório como sendo do tipo 2.

Os dados coletados pelo perfilador Satlantic, tais como concentração de clorofila, temperatura da água e coeficiente de retroespalhamento do material particulado sugerem uma divisão do reservatório em maio, período de cheia, em dois compartimentos. Um sendo a 
NASCIMENTO, R. F. F.; ALCÂNTARA, E.; KAMPEL, M.; STECH, J. L. Caracterização limnológica do reservatório hidrelétrico de Itumbiara, Goiás, Brasil. Ambi-Agua, Taubaté, v. 6, n. 2, p. 143-156, 2011. (doi:10.4136/ambi-agua.191)

região do rio Corumbá e o outro, o corpo do reservatório como um todo. Em setembro, época de vazante, o reservatório se apresenta de forma mais homogênea, não sendo, portanto, compartimentado.

\section{AGRADECIMENTOS}

Os autores agradecem à FAPESP (Projeto: 2007/08103-2) pelo auxílio financeiro. Renata Nascimento agradece ao CNPq pela bolsa de mestrado.

\section{REFERÊNCIAS}

ALCÂNTARA, E. H.; STECH, J. L.; LORENZZETTI, J. A.; BONNET, M. P.; CASAMITJANA, X.; ASSIREU, A. T.; NOVO, E. M. Remote sensing of water surface temperature and heat flux over a tropical hydroelectric reservoir. Remote Sensing of Environment, v. 114, p. 2651-2665, 2010a.

ALCÂNTARA, E.; NOVO, E. M.; STECH, J. L.; ASSIREU, A. T.; NASCIMENTO, R.; LORENZZETTI, J.; SOUZA, A. Integrating historical topographic maps and SRTM data to derive the bathymetry of a tropical reservoir. Journal of Hydrology, v. 389, p. 311-316, 2010b.

ALCÂNTARA, E. H.; BONNET, M. P.; ASSIREU, A. T.; STECH, J. L.; NOVO, E. M. L. M.; LORENZZETTI, J. A. On the water thermal response to the passage of cold fronts: initial results for Itumbiara reservoir (Brazil). Hydrology and Earth System Sciences Discussions, v. 7, p. 9437-9465, 2010c.

BANDYOPADHYAY, S.; MAULIK, U. An evolutionary technique based on K-Means algorithm for optimal clustering in $\mathrm{R}^{\mathrm{N}}$. Information Sciences, v. 146, p. 221-237, 2002. http://dx.doi.org/10.1016/S0020-0255(02)00208-6

BAZZOLI, N.; MESQUITA, T. L.; SANTOS, G. B.; RIZZO, E. Análise comparativa da reprodução de Astyanax bimaculatus (Pisces: Characidae) nos reservatórios de Furnas, Marimbondo e Itumbiara. Bios, v. 5, n. 5, p. 7-15, 1997.

CABRAL, A. P.; MANTOVANI, J. E.; COSTA, M. P. F.; LIMA, R. A. F.; NOVO, E. M. L. M. Efeitos da concentração e da granulometria na assinatura espectral do material inorgânico em suspensão. In: SIMPÓSIO BRASILEIRO DE SENSORIAMENTO REMOTO, 6., 1990, Manaus. Anais... São José dos Campos: INPE, 1990. p. 496-504. Printed, On-line. ISBN 978-85-17-00051-5. (INPE-7870-PRE/3710). Disponível em: <http://urlib.net/dpi.inpe.br/marte@80/2008/08.18.17.36>. Acesso em: 26 out. 2009.

CALIJURI, M. C. A comunidade fitoplanctônica em um reservatório tropical (Barra Bonita, SP). 1999. 211f. Tese (Livre-Docência) - Escola de Engenharia de São Carlos, Universidade de São Paulo, São Carlos, 1999.

CAMARGO, E. C. G.; FUCKS, S. D.; CÂMARA, G. Análise Espacial de Superfícies. In: DRUCKS, S.; CARVALHO, M. S.; CÂMARA, G.; MONTEIRO, A. V. M. (Ed.). Análise espacial de dados geográficos. Brasília: EMBRAPA, 2004.

CHOUBEY, V. K.; SUBRAMANIAN, V. Spectral response of suspended sediments in water under controlled conditions. Journal of Hydrology, v. 122, p. 301-308, 1991. http://dx.doi.org/10.1016/0022-1694(91)90184-J 
NASCIMENTO, R. F. F.; ALCÂNTARA, E.; KAMPEL, M.; STECH, J. L. Caracterização limnológica do reservatório hidrelétrico de Itumbiara, Goiás, Brasil. Ambi-Agua, Taubaté, v. 6, n. 2, p. 143-156, 2011. (doi:10.4136/ambi-agua.191)

FELGUEIRAS, C. A. Modelagem ambiental com tratamento de incertezas em sistemas de informação geográfica: o paradigma geoestatístico por indicação. 1999. 212 p. (INPE-8180-TDI/760). Tese (Doutorado em Computação Aplicada) - Instituto Nacional de Pesquisas Espaciais - INPE, São José dos Campos, 1999.

FOUGNIE, B.; FROUIN, R.; LECOMTE, P.; DESCHAMPS, P. Y. Reduction of Skylight Reflection Effects in the Above-Water Measurement of Diffuse Marine Reflectance. Applied Optics, v. 38, n. 18, p. 3844-3856, 1999. http://dx.doi.org/10.1364/AO.38.003844

FURNAS. Relatório sócio-ambiental 2008: o fio que nos une. Disponível em: $<$ http://sociedadesustentavel.terra.com.br/upload/mercados_new_pdf/Furnas_relatorio_s ocioambiental-2009.pdf>. Acesso em: 15 ago. 2011.

GITELSON, A. A.; KEYDAN, G. P. Remote sensing of inland surface water quality measurements in the visible spectrum. Acta hydrophys, v. 34, n. 1, p. 5-27, 1990.

GOODIN, D. G.; HAN, L.; FRASER, R. N.; RUNDQUIST, C.; STEBBINS, W. A.; SCHALLES, J. F. Analysis of suspended solids in water using remotely sensed high resolution derivative spectra. Photogramm. Eng. Remote Sensing, v. 59, n. 4, p. 505510, 1993.

HOJO, R. E. S.; SANTOS, G. B.; BAZZOLI, N. Reproductive biology of Moenkhausia intermedia (Eigenmann) (Pisces, Characiformes) in Itumbiara reservoir, Goiás, Brazil. Revista Brasileira de Zoologia, v. 21, n. 3, p. 519-524, 2004. http://dx.doi.org/10.1590/S0101-81752004000300015

JOURNEL, A. G. Fundamentals of geostatistics in five lessons. Stanford: Stanford Center for Reservoir Forecasting Applied Earth Sciences Department, 1988. 85 p.

KIRK, J. T. O. Light and photosynthesis in aquatic ecosystems. London: Cambridge University Press, 1994. http://dx.doi.org/10.1017/CBO9780511623370

LIEW, S. C.; LIN, I. I.; KWOH, L. K.; HOLMES, M.; TEO, S.; GIN, K.; LIM, H. Spectral reflectance signatures of case II waters: potential for tropical algal bloom monitoring using satellite ocean color sensors. In: SEMINAR ON MARINE AND FISHERIES SCIENCES, 10. 1999, Melaka. Proceedings... Melaka, 1999. p. 1-8. Disponível em $<$ http://www.crisp.nus.edu.sg/ liew/txt/LiewSC_JSPS99.PDF>. Acesso em: 12 fev. 2009.

LIU, Y.; ISLAM, M. A.; GAO, J. Quantification of shallow water quality parameters by means of remote sensing. Progress in Physical Geography, v. 27, n. 1, p. 24-43, 2003. http://dx.doi.org/10.1191/0309133303pp357ra

LOPES, J. E. G.; SANTOS, R. C. P. Capacidade de reservatórios. São Paulo: Escola Politécnica da Universidade de São Paulo, 2002.

MCFEETERS, S. K. The use of the Normalized Difference Water Index (NDWI) in the delineation of open water features. International Journal of Remote Sensing, v. 17, p. 1425-1432, 1996. http://dx.doi.org/10.1080/01431169608948714

MENDONÇA, R. F. Origem e destino do carbono em sistemas límnicos - uso de técnicas isotópicas em reservatórios e lagos rasos. 2007. 58f Dissertação (Mestrado) Universidade Federal de Juiz de Fora, Juiz de Fora, 2007. 
NASCIMENTO, R. F. F.; ALCÂNTARA, E.; KAMPEL, M.; STECH, J. L. Caracterização limnológica do reservatório hidrelétrico de Itumbiara, Goiás, Brasil. Ambi-Agua, Taubaté, v. 6, n. 2, p. 143-156, 2011. (doi:10.4136/ambi-agua.191)

MOBLEY, C. D. Light and water: radiative transfer in natural waters. San Diego: Academic Press, 1994. $592 \mathrm{p}$.

SOUTH DAKOTA SCHOOL OF MINES AND TECHNOLOGY. Department of Mathematics and Computer Science. MRT MODIS Reprojection Tool User's Manual: , USGS EROS Data Center. 2002. p. 1-57. Disponível em< http://nrm.salrm.uaf.edu/ dverbyla/MODIS_Land_Products/pdf_documents/MODIS_R eprojection_Tool_3.0_Manual.pdf >.Acesso: 15 ago. 2011.

MUELLER, J. L.; FARGION, G. S.; MCCLAIN, C. R. Oceans optics protocols for satellite ocean color sensor validation. 4. rev. Greenbelt: NASA, 2002. 76 p. Volume IV: Inherent optical properties.

NASCIMENTO, R. F. F.; ALCÂNTARA, E. H.; KAMPEL, M.; STECH, J. L.; NOVO, E. M. L. M.; FONSECA, L. M. G. O algoritmo Support Vector Machines (SVM): avaliação da separação ótima de classes em imagens CCD-CBERS-2. In: SIMPÓSIO BRASILEIRO DE SENSORIAMENTO REMOTO, 14., 2009, Natal. Anais... São José dos Campos: INPE, 2009. p. 2079-2086. ISBN 978-85-17-00044-7. (INPE-15957PRE/10566). Disponível em: <http://urlib.net/dpi.inpe.br/sbsr@80/2008/10.20.10.59>. Acesso em: 3 jan. 2010.

NOVO, E. M. L. M.; STEFFEN, C. A.; BRAGA, C. Z. F. Results of a laboratory experiment retaling spectral reflectance total suspended solids. Remote Sensing of Environment, v. 36, p. 67-72, 1991. http://dx.doi.org/10.1016/0034-4257(91)90031-Z

NUSH, E. A. Comparison of different methods for chlorophyll and phaeopigment determination. Arch. Hydrobiol., v. 14, p. 14-39, 1980.

OLIVEIRA, W. Hidrelétrica e a importância do EPIA/RIMA em empreendimentos para produção de energia com desenvolvimento sustentável. Piracicaba: Universidade Metodista de Piracicaba, 2006. 234p.

PRADO, R. B. Geotecnologias aplicadas à análise espaço-temporal do uso e cobertura da terra e qualidade da água do reservatório de Barra Bonita, SP, como suporte à gestão de recursos hídricos. 2004. Tese (Doutorado) - Escola de Engenharia de São Carlos, Universidade de São Paulo, São Carlos, 2004.

PRIEUR, L.; SATHYENDRANATH, S. An optical classification of coastal and oceanic waters based on the specific spectral absorption curves of phytoplankton pigments, dissolved organic matter, and other particulate materials. Limnology and Oceanography, v. 26, n. 4, p. 671-689, 1981. http://dx.doi.org/10.4319/lo.1981.26.4.0671

ROSA, P. G. Comunidade zooplanctônica de quatro reservatórios do centro-oeste do Brasil: abundância e biomassa em carbono. 2005. 70f. Monografia (Graduação em Ciências Biológicas) - Universidade Federal do Estado do Rio de Janeiro, Rio de Janeiro, 2005. 
NASCIMENTO, R. F. F.; ALCÂNTARA, E.; KAMPEL, M.; STECH, J. L. Caracterização limnológica do reservatório hidrelétrico de Itumbiara, Goiás, Brasil. Ambi-Agua, Taubaté, v. 6, n. 2, p. 143-156, 2011. (doi:10.4136/ambi-agua.191)

VIEIRA, A. B. C.; SALVADOR JR., L. F.; MELO, R. M. C.; SANTOS, G. B.; BAZZOLI, N. Reproductive biology of the peacock bass Cichla piquiti (Perciformes: Cichlidae), an exotic species in a neotropical reservoir. Neotropical Ichthyology, v. 7, n. 4, p. 745750, 2009.

http://dx.doi.org/10.1590/S1679-62252009000400024

WETZEL, R. G.; LIKENS, G. E. Limnological Analyses. 2. ed. New York: Springer-Verlag, 1991. 